\section{Discussion}

The mechanism of bronchoconstriction and the relative effects of sympathomimetics and anticholinergics may depend on the clinical type of disease. Evaluation and comparison of results of trials on bronchodilators may be hampered by the fact that "mixed" groups of patients with airways obstruction are used in the studies. We have therefore tried to select and characterize our material according to stated clinical criteria.

In the present series of bronchitics Sch 1000 produced a larger increase in SGaw measured two hours after the inhalation of the drug than salbutamol. The bronchodilation effect of Sch 1000 also seemed to persist longer, since inhalation of isoprenaline after four hours of follow-up produced a larger increase in PEF in the salbutamol experiment than in the Sch 1000 experiment. Hence with the therapeutically recommended doses used Sch 1000 seems to compare favourably with salbutamol with regard to the bronchodilation effect in patients with chronic bronchitis.

The lack of side effects, such as on heart rate or others, after the anticholinergic drug in this short-term experiment may also be noted. The effect on the mucociliary performance cannot be assessed from this experiment, but dryness of mouth was reported only on specific inquiry and occurred twice after both salbutamol and Sch 1000, and in four cases after placebo. If this lack of side effects is substantiated in long-term use it will be an additional good feature of this form of delivery of the anticholinergic substance.

In asthmatics Lahdensuo et al. (1973) found a larger mean increase in PEF after salbutamol than after Sch 1000 by using the same technique of investigation as in the present study. The different findings in the two studies may be explained by the hypothesis of Booij-Noord et al. (1970) that bronchitics are more sensitive to the vagal reflex action than asthmatics.

\section{References}

Altounyan, R. E. C. (1964). Thorax, 19, 406

Booij-Noord, H., Orie, N. G. M., Berg, W. C., and De Vries, K. (1970). In Proceedings of the Third International Symposium on Bronchitis at Groningen, the Netherlands, 23-26 September 1969, p. 316.

Crompton, G. K. (1968). Thorax, 23, 46.

Lahdensuo, A., Vilianen, A. A., and Muittari, A. (1973). Scandinavian Fournal of Clinical and Laboratory Investigation, 31, Suppl. No. 130, p. 16.

Poppius, H. (1965). Annales Academiae Scientiarum Fennicae, A, Suppl. No. 114.

Poppius, H., Salorinne, Y., and Viljanen, A. A. (1972). Bulletin de Physiopathologie Respiratoire, 8, 643.

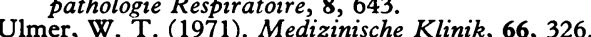

Woitowitz, H. J., Buchheim, F. W., and Woitowitz, R. (1967). Praxis der Pneumologie, 21, 449.

\title{
Abuse of Drugs "for Kicks": A Review of 252 Admissions
}

\author{
JOHN A. H. FORREST, RICHARD A. TARALA
}

British Medical fournal, 1973, 4, 136-139

\section{Summary}

Abuse of drugs "for kicks" is becoming more common in Great Britain. This article reviews 252 consecutive cases of drug abuse admitted to the Regional Poisoning Treatment Centre, Royal Infirmary, Edinburgh, during 1971 and 1972. Of the 189 patients (146 males and 43 females; mean age 20 years) $72 \%$ of admissions occurred between 6 p.m. and 8 a.m., and Saturday was the most common day for admissions. The commonest source of referral was via the police or ambulance service. Barbiturates were the drugs most often abused, followed by LSD (lysergide) and Mandrax (methaqualone and diphenhydramine). Sixty-five per cent. of patients had previously abused drugs. Medical care was required in $\mathbf{4 5} \%$ of the admissions. Sixty per cent. were in social class 4 or 5 and psychiatric and social support was required in only a small minority of patients.

\section{Introduction}

Many recent publications have emphasized the continued rise in admissions to hospital as a result of self-poisoning and the burden this places on the Health Services (Matthew et al., 1969; Matthew and Lawson, 1970; Sydney Smith and Davison, 1971;

\footnotetext{
Regional Poisoning Treatment Centre, Royal Infirmary, Edinburgh EH3 9YW

JOHN A. H. FORREST, M.B., M.R.C.P., Medical Registrar

RICHARD A. TARALA, M.B., M.R.C.P., Senior House Officer
}

Baird et al., 1972; Lawson and Mitchell, 1972; Patel et al., 1972; Smith, 1972). During 1970 at the Regional Poisoning Treatment Centre, Royal Infirmary, Edinburgh, an increase in the number of patients taking drugs "for kicks"- that is, for their pleasurable effect in order to become intoxicated-was noted. Little information has been published about this aspect of selfpoisoning; hence in 1971 a prospective study was started to ascertain the incidence of admissions to this centre resulting from the taking of drugs for kicks, the type of drugs involved, and the characteristics of these patients. This paper reviews the 252 admissions resulting from this type of drug taking during 1971 and 1972.

\section{Patients and Methods}

The Regional Poisoning Treatment Centre serves a population of about half a million in Edinburgh and the surrounding district, and most poisoned patients presenting at other hospitals are referred here. All poisoned patients from 12 years of age are admitted, regardless of the severity of the poisoning, and this admission policy has not changed for many years (Matthew and Lawson, 1970). In 1962 (Kessel et al., 1964) and 1967 (Matthew et al., 1969) 90 and $95 \%$ respectively of all poisoned adults admitted to hospital from the catchment area passed through this unit.

All patients were examined on admission by a resident medical officer and certain facts recorded. As soon as practicable after regaining consciousness all patients were examined by both a physician and a psychiatrist and only if both were in agreement that from the history, clinical examination, or circumstantial evidence or a combination of these factors that the admission was the direct result of having taken drugs for kicks was the patient included in the study.

This study does not include 56 patients admitted because of 
severe alcoholic intoxication during 1971 and 1972, nor does it include any drug-dependent patients who took drugs in an accidental, manipulative, or suicidal manner. The type of drug taken is based on information obtained from patients or friends as no laboratory screening techniques could possibly include all the different drugs that could have been involved. The father's social class was recorded if the patient was still in full-time education.

\section{Results}

\section{GENERAL ASPECTS}

There were 252 admissions during the two-year period of the study involving 189 different patients. There were 116 admissions in 1971 and 136 in 1972. Altogether, 159 patients were admitted on one occasion, 15 patients on two occasion, six patients on three occasions, and nine on four or more occasions. Twenty-four of those repeating were males and six were females.

There were 146 males and 43 females (fig. 1). The mean age was 20.8 years in males and 17.5 in females. In males the peak incidence was in the range 19 to 21 years and for females 16 to 18 years. A total of 105 patients $(55 \%)$ were under the age of 20 years.

The percentage of admissions in the second, third, and fourth quarters $(25,33$, and $28 \%$ respectively) was much higher than for the first quarter $(14 \%)$. Saturday was the commonest day for admissions $(21 \%)$, there being little difference between the other days (12-14\%). Forty-nine per cent. of admissions took place from Friday to Sunday.

The peak period for admission was between 10 p.m. and 2 a.m. (fig. 2 ); $72 \%$ of the total occurring between 6 p.m. and 8 a.m., $52 \%$ from 10 p.m. to 8 a.m.

The most common source of referral was via the police or ambulance service (table I). General practitioners referred only 20 of the admissions $(8 \%)$, while $64(25 \%)$ were selfpresnetations.

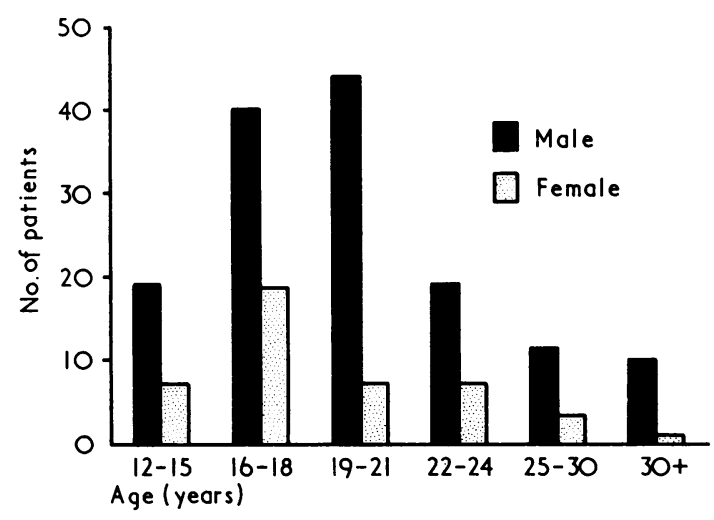

FIG. 1-Age and sex distribution of patients in study.

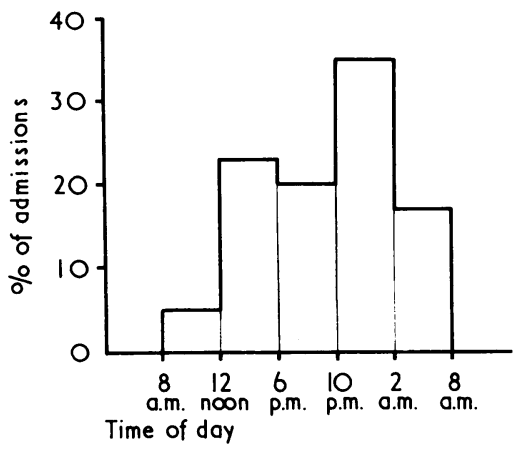

FIG. 2-Time of admission to hospital.
TABLE I-Source of Referral of 252 Admissions

\begin{tabular}{|c|c|c|c|c|}
\hline & & & No. of Cases & $\%$ \\
\hline 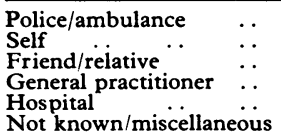 & $\begin{array}{l}\ldots \\
\cdots \\
\cdots \\
\cdots\end{array}$ & $\begin{array}{l}\ldots \\
\cdots \\
\cdots \\
\cdots\end{array}$ & $\begin{array}{l}89 \\
64 \\
45 \\
20 \\
10 \\
24\end{array}$ & $\begin{array}{r}35 \\
25 \\
18 \\
8 \\
4 \\
10\end{array}$ \\
\hline
\end{tabular}

PATTERN OF DRUGS INVOLVED

The principal drugs involved and their route of administration are shown in table II. Barbiturates accounted for 87 admissions $(35 \%)$. There were 41 admissions as a result of Mandrax (methaqualone and diphenhydramine) abuse, and 52 cases of LSD (lysergide) abuse. The most popular barbiturate was Tuinal (amylobarbitone and quinalbarbitone)-38 admissions, 12 being intravenous administration-closely followed by Nembutal (pentobarbitone)-28 admissions, four intravenousSeconal (quinalbarbitone), Amytal (amylobarbitone), and other barbiturates were less commonly taken. Amphetamines were responsible for 24 admissions. Opiates accounted for only 16 admissions, four being secondary to heroin abuse. The miscellaneous category includes four persons admitted after taking cannabis.

TABLE II-Principal Drugs and Route of Administration. Figures in Parentheses are Schoolchildren

\begin{tabular}{|c|c|c|c|c|c|}
\hline & & \multirow[t]{2}{*}{ No. of Cases } & \multirow[t]{2}{*}{$\%$} & \multicolumn{2}{|c|}{ Route } \\
\hline & & & & Oral & Intravenous \\
\hline $\begin{array}{l}\text { Barbiturates } \\
\text { Mandrax } \\
\text { LSD .. } \\
\text { Opiate .. } \\
\text { Amphetamines } \\
\text { Miscellaneous } \\
\text { Not known }\end{array}$ & $\begin{array}{l}\ldots \\
\ldots \\
\cdots \\
\cdots \\
\ldots\end{array}$ & $\left.\begin{array}{ll}87 & (10) \\
41 & (4) \\
52 & (7) \\
16 & \\
24 & (1) \\
17 \\
15\end{array}\right\}$ & $\begin{array}{r}35 \\
16 \\
21 \\
6 \\
10 \\
6 \\
6\end{array}$ & $\begin{array}{r}64 \\
41 \\
52 \\
3 \\
22 \\
17 \\
15\end{array}$ & $\begin{array}{r}23 \\
0 \\
0 \\
13 \\
2 \\
0 \\
0\end{array}$ \\
\hline
\end{tabular}

Excluding alcohol, more than one drug was taken on 46 admissions $(18 \%$ ) while alcohol in conjunction with a drug was taken on 88 admissions ( $35 \%)$. These secondary drugs comprised 15 barbiturates (predominantly Tuinal and Nembutal), nine Mandrax, six cannabis, five amphetamine, and the remainder were a variety of drugs including LSD and phenytoin.

\section{MEDICAL ASPECTS}

When using the criteria of Matthew and Lawson (1970), 117 admissions $(46 \%)$ were grade 0 on admission, $105(42 \%)$ grade 1 unconscious, $22(9 \%)$ grade 2 , five $(2 \%)$ grade 3 , and three $(1 \%)$ grade 4 . Of the 30 admissions unable to obey vocal commands 29 had regained consciousness within 12 hours of admission and the remaining patient within 24 hours.

Gastric aspiration and lavage were carried out on 53 admissions $(21 \%)$ according to the criteria of Matthew et al. (1966). Endotracheal intubation was required on six occasions only. Assisted ventilation, intravenous fluids, and bladder catheterization were not required. Hypotension (systolic blood pressure less than $80 \mathrm{~mm} \mathrm{Hg}$ ) was noted on five occasions only and responded to elevation of the foot of the bed. Hypothermia was not encountered. Sedation with either parenteral chlorpromazine or diazepam was required for 39 admissions (15\%). Forty-eight per cent. of LSD admissions and $18 \%$ of amphetamine admissions required sedation.

Tests for Australia antigen as determined by immunoelectrophoresis were performed on 19 patients who were regularly taking drugs intravenously and in all cases results were negative. Liver function tests were abnormal in three of these patients. 
A total of 232 admissions ( $92 \%$ ) could be discharged from the unit within 24 hours of admission, 16 within 48 hours, only three being detained longer than 48 hours. There were no deaths.

\section{PSYCHIATRIC ASPECTS}

Sixty-four patients ( $34 \%$ ) were considered to have no psychiatric abnormality while a diagnosis of a personality disorder was made in a further $26 \%$ (table III). Of those with a psychiatric illness five were depressed. Fifty patients $(26 \%)$ had previously been admitted to this centre, while 57 patients $(30 \%)$ had received psychiatric treatment in the past- 46 as inpatients. Seventeen patients were regarded as alcoholics and a further 24 were taking alcohol excessively. A diagnosis of drug addiction was made in 35 patients $(19 \%)$ while another $88(47 \%)$ were or had been drug abusers. Only eight patients were transferred from this unit direct to inpatient psychiatric care, a further 21 being given an outpatient appointment.

TABLE III-Psychiatric Diagnosis in 189 Patients

\begin{tabular}{|c|c|c|c|c|c|}
\hline & & & & No. of Cases & $\%$ \\
\hline $\begin{array}{l}\text { No psychiatric illness, } \\
\text { No psychiatric illness, } \\
\text { Drug addiction . . } \\
\text { Alcoholism } \\
\text { Psychiatric illness } \\
\text { Not known }\end{array}$ & 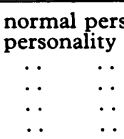 & $\begin{array}{l}\text { ality } \\
\text { order } \\
\ldots \\
\cdots \\
\ldots \\
\ldots\end{array}$ & $\begin{array}{l}\cdots \\
\cdots \\
\cdots \\
\cdots\end{array}$ & $\begin{array}{l}64 \\
49 \\
35 \\
17 \\
11 \\
13\end{array}$ & $\begin{array}{r}34 \\
26 \\
18 \\
9 \\
6 \\
7\end{array}$ \\
\hline
\end{tabular}

\section{SOCIAL ASPECTS}

Altogether, 112 patients $(60 \%)$ belonged to social classes 4 and 5 while only 10 patients (5\%) belonged to classes 1 and 2 (table IV). There were eight full-time students admitted and 27 schoolchildren (14 boys and 13 girls). Their ages ranged from 12 to 18 years (mean 15 years). Table II shows the drugs taken by these schoolchildren. Seven had taken LSD. Seven (six girls) had previously abused drugs and only one repeated during the period of the study. Twelve were thought to have a personality disorder or to be exhibiting adolescent crisis behaviour.

TABLE IV-Social Class

\begin{tabular}{|c|c|c|c|c|c|c|}
\hline & \multicolumn{6}{|c|}{ Social Class } \\
\hline & 1 & 2 & 3 & 4 & 5 & $\stackrel{\text { Not }}{\text { known }}^{\text {not }}$ \\
\hline No. of patients $(\%) \ldots$ & $1(1)$ & $9(5)$ & $33(17)$ & $41(22)$ & $71(38)$ & $34(17)$ \\
\hline $\begin{array}{l}\text { Distribution of } \\
\text { population of Scotland } \\
\text { age } 15-24 \text { years }\end{array}$ & 1.5 & $6 \cdot 0$ & $60 \cdot 0$ & $22 \cdot 0$ & $7 \cdot 0$ & 3.5 \\
\hline
\end{tabular}

Sixty-five patients $(34 \%)$ were unemployed at the time of admission. An accurate record of criminal behaviour was made in 1971 only. Of the 99 patients (78 male and 21 female) admitted in that year 24 males (31\%) and three females had been in prison, while a further 14 males and three females had police convictions.

\section{Discussion}

Drug abuse is becoming an increasing problem in Britain, with a consequent increase in the demands on the health services. During 1971 and 1972 there were 252 admissions as a result of drug abuse representing $7 \%$ of the total admissions to this centre. Seventy-seven per cent. were males and the mean age of all admissions was 20 years (range 12-54 years). The mean age for females (17.5 years) was less than for males (20.8 years). Fifty-five per cent. of admissions were teenagers and $14 \%$ were under 16 years of age. The ratio of males to females $(3 \cdot 4: 1)$ is in contrast to that found in self-poisoning in general, where it is $1: 1 \cdot 5$.

Also in contrast to self-poisoning, Saturday was the most common day for admissions (Matthew et al., 1969). September was the busiest month, possibly owing to the International Festival which takes place in Edinburgh at that time. The repetition rate of $16 \%$ over the two-year period is lower than that reported for self-poisoning (Matthew et al., 1969; Lawson and Mitchell, 1972). Again in contrast to self-poisoning is the significantly greater percentage of admissions between 10 p.m. and 8 a.m. (Matthew et al., 1969). The percentage taking alcohol differs little from that in patients admitted to this unit for selfpoisoning (Brown, 1970), though the number taking a second drug $(18 \%)$ is somewhat less. The most common presentation was for the patient to be found by the police in a stuporose or agitated condition and then brought to the accident and emergency department. Because most admissions occur late at night and often after parties outside the patient's own district, general practitioners probably see very little of this aspect of the problems of drug abuse.

Tuinal was the most popular barbiturate used and was often taken intravenously. Since opiates are difficult to obtain in Edinburgh, and as they are not prescribed for outpatients, only $6 \%$ of admissions resulted from this group of drugs. "Mainline" addicts therefore tend to use Tuinal or Nembutal as substitutes. This leads to a more rapid deterioration in the condition of their veins. There has been controversy recently (Brown, 1973; Green, 1973; Mathers, 1973; Matthew, 1973) about the abuse of Mandrax, and in our own experience it is especially abused by teenagers, including schoolchildren. It is often taken in conjunction with alcohol when it gives an especially strong "buzz." Since Mandrax is very difficult to dissolve in water no admission resulted from its intravenous use; indeed addicts who "mainline" seldom use Mandrax as a substitute for opiates.

Of the LSD admissions $48 \%$ required sedation with either intravenous diazepam or intramuscular chlorpromazine. Contrary to previous claims (Levy, 1971) it was found that intravenous diazepam was in no way superior to chlorpromazine given in adequate dosage - that is, $100 \mathrm{mg}$ intramuscularly. Indeed some patients required chlorpromazine after diazepam had failed to achieve sedation. No patient became permanently psychotic after LSD, though flashbacks were observed in one patient. Most of the drugs misused were acquired illegally in public houses or at parties. However, we were struck by the number of occasions on which unkempt, long-haired youths asked for and were given barbiturates or Mandrax as night sedation by general practitioners to whom they presented as "visitors."

Several patients taking drugs regularly intravenously had previously been in hospital with jaundice. None were positive for Australia antigen, a finding in keeping with other clinical experience in Edinburgh-namely, that these patients are apparently only transiently Australia-antigen positive. Most patients were in social classes 4 and 5 . There were only eight full-time students and this, coupled with the highest admission rate during July to September-the University vacationsuggests that student drug taking in Edinburgh may not be extensive.

It is noteworthy that $65 \%$ of the patients were classified either as drug addicts or had been or were abusing drugs. Of those admitted on one occasion very few were thought to be suffering from a psychiatric illness and few required social support. Almost exclusively those who were admitted on more than one occasion were in social class five, were unemployed, had criminal records, were habituated drug abusers, and were psychopaths. This group, who clearly would have benefited from social support, usually rejected it and psychiatric help was seldom indicated. Continued psychiatric supervision, either as an inpatient or outpatient, was arranged in only $16 \%$ of patients, 
which is much less than for self-poisoning in general (Matthew et al., 1969). An appreciable number of patients refused further psychiatric help and many of those given outpatient appointments failed to attend. Only $11(6 \%)$ were thought to be suffering from a psychiatric illness. Of those regarded as having a personality disorder most were psychopaths. Each patient was seen by a medical social worker but it was found impossible to evaluate the help offered.

This study shows that drug abusers place a significant work load on the police and hospital services. Most admissions occurred after 10 p.m., the patients were often abusive, demanding, and disruptive, thus placing great strain on junior medical and nursing staff. Rather less than half the admissions required resuscitation, gastric aspiration and lavage, or sedation. Few needed or accepted psychiatric or social support. The study supports the view that, like alcoholic intoxication, and unlike self-poisoning in general (Greer and Bagley, 1971; Kennedy, 1972) there is often little to be gained from the psychiatric point of view from admitting drug abusers to hospital, and admission should be mainly based on the patient's medical condition when examined in the casualty department. This knowledge should prove of value in areas where medical hospital beds are at a premium.
We are indebted to Dr. Henry Matthew for encouragement and helpful advice, to the psychiatrists who co-operated in the study, and to the nursing staff and resident medical officers. We are also indebted to Miss A. S. Bell for expert secretarial help.

\section{References}

Baird, R. N., Noble, J., and McLean, D. (1972). British Medical fournal, 3,90 .

Brown, C. G. (1973). British Medical fournal, 2, 55

Brown, S. S. (1970). Paper presented to IV Congress of Poison Control Centres, Yugoslavia.

Green, R. (1973). British Medical Fournal, 2, 244.

Greer, S., and Bagley, C. (1971). British Medical fournal, 1, 310.

Kennedy, P. (1972). British Medical fournal, 4, 255.

Kessel, N., et al. (1964). Scottish Medical fournal, 9, 333.

Lawson, A. A. H., and Mitchell, I. (1972). British Medical fournal, 4, 153. Levy, R. M. (1971). Lancet, 1, 1297.

Mathers, G. (1973). British Medical fournal, 2, 243.

Matthew, H. (1973). British Medical fournal, 2, 367

Matthew, H., and Lawson, A. A. H. (1970). Treatment of Common Acute Poisonings, 2nd edn. Edinburgh, Churchill Livingstone.

Matthew, H., Mackintosh, T. F., Tompsett, S. L., and Cameron, J. C. (1966). British Medical Fournal, 1, 1333.

Matthew, H., Proudfoot, A. T., Brown, S. S., and Aitken, R. C. B. (1969). British Medical fournal, 3, 489.

Patel, A. R., Roy, M., and Gilson, G. M. (1972). Lancet, 2, 1099.

Patel, A. R., Roy, M., and Gilson, G. M. (1972). La

Sydney Smith, J., and Davison, K. (1971). British Medical fournal, 4, 412

\title{
Interdependence of Exchangeable Sodium and Plasma Renin Concentration in Determining Blood Pressure in Patients Treated by Maintenance Dialysis
}

\author{
S. M. ROSEN, P. J. A. ROBINSON
}

British Medical fournal, 1973, 4, 139-143

\section{Introduction}

\section{Summary}

Plasma renin concentration and exchangeable sodium were measured in 13 patients with terminal renal failure maintained by dialysis therapy. Blood pressure in seven "responsive" patients was controlled by ultrafiltration but was not controlled in six "resistant" patients. Plasma renin concentration was inversely related to exchangeable sodium in the responsive group but was inappropriately high for the level of exchangeable sodium in the resistant group. There was a better correlation between mean blood pressure and the product of plasma renin concentration and exchangeable sodium than with renin concentration alone.

These results indicate that a severely diseased kidney can respond to changes in exchangeable sodium by alterations in renin secretion and they also support the concept that the potential pressor effect of renin is modified by exchangeable sodium. The product of the two factors might be used to determine the "effective" plasma renin concentration in respect of blood pressure.

Leeds (St. James's) University Hospital, Leeds LS9 7TF

S. M. ROSEN, M.B., F.R.C.P., Consultant Renal Physician

P. J. A. ROBINSON, M.B., M.R.C.P., Research Fellow

The role of renin as a pressor agent in patients with terminal renal failure maintained by dialysis therapy is the subject of continuing speculation. Evidence in favour of a part played by renin in the maintenance of hypertension stems largely from the fact that patients with severe uncontrollable hypertension have a very high plasma renin concentration, and bilateral nephrectomy reduces the plasma renin with a concomitant reduction in blood pressure (Onesti et al., 1968; Brown et al., 1969). Kidneys from such patients with severe hypertension have a higher content of renin than those with controlled blood pressure (Vertes et al., 1969).

However, the correlation between plasma renin concentration and blood pressure is not close, owing to a wide scatter of values (Brown et al., 1969; Wilkinson et al., 1970). Furthermore, plasma renin concentration may rise during a dialysis treatment, though a reduction in blood pressure may be effected (Bianchi et al., 1972).

During ultrafiltration with dialysis therapy there is usually a reduction in blood pressure associated with the removal of salt and water (Shaldon et al., 1963). Loss of sodium in a normal person causes a rise in plasma renin concentration (Brown et al., 1963; Veyrat et al., 1964; Bull et al., 1970), but evidence from dogs indicates that the potential pressor effect of this increase in plasma renin is offset by the reduction of body sodium (Bianchi et al., 1968).

This suggests that a relation between renin and blood pressure may be found only if the effective pressor potential of the renin is calculated by taking into account other factors which may alter the capacity of blood vessels to respond to the biological products of renin.

This paper studies the inter-relation of renin and sodium and blood pressure in terminal renal failure. 